\title{
Nanoscale
}

PAPER
View Article Online

View Journal I View Issue
Check for updates

Cite this: Nanoscale, 2019, 11, 7335

\section{(Photo)electrocatalysis of molecular oxygen reduction by S-doped graphene decorated with a star-shaped oligothiophene $\uparrow$}

\begin{abstract}
Anastasios Stergiou,* Dimitris K. Perivoliotis (iD) and Nikos Tagmatarchis (iD *
Heteroatom-doped graphene-based materials attract great interest as non-metal electrocatalysts for the oxygen reduction reaction (ORR). In this work, a straightforward approach was described to prepare nanoensembles of star-shaped oligothiophene 1 supramolecularly immobilized on sulfur-doped graphene sheets (SG). The 1/SG ensemble was comprehensively characterized by Raman and IR spectroscopy and morphologically imaged by HR-TEM, while the loading of 1 onto SG was estimated by TGA under an inert atmosphere. Based on detailed electrochemical and electrocatalytic assays, 1/SG was proved to be a highly efficient and stable electrocatalyst toward the ORR. The high catalytic activity of 1/SG was attributed to the (a) presence of chemical defects, induced by the insertion of electron rich sulfur within the lattice of SG, (b) existence of structural defects, due to the generation of vacancies along the carbon lattice in SG, and (c) high and homogeneous coverage of the SG surface by the sulfur-rich star-shaped oligothiophene 1. In addition, the optical properties of 1/SG were screened by UV-Vis and steady-state and time-resolved $\mathrm{PL}$ and the development of strong photoinduced intra-ensemble electronic interactions within the ensemble was revealed. Exploiting the latter, by photoirradiating 1/SG, a significantly improved photoelectrocatalytic activity towards the ORR was observed.
\end{abstract}

Received 22nd February 2019, Accepted 19th March 2019

DOI: 10.1039/c9nr01620a

rsc.li/nanoscale
The generation of ORR active sites within the surface of graphene, mainly through elemental doping with sulfur and/ or nitrogen atoms, is a critical aspect towards functional graphene-based cathodes. ${ }^{5}$ A great effort has already been made in this field unveiling that the enhanced ORR efficiency of doped graphene is related both to chemical defects, induced by the insertion of electron rich elements (i.e. sulfur), and the presence of structural defects (i.e. generation of vacancies along the carbon lattice). ${ }^{6}$ The insertion of heteroatoms across the graphitic lattice breaks the aromaticity of the extended conjugated network of graphene and provides unpaired electrons enhancing conductivity, ${ }^{7}$ and generates structural and chemical defects resulting in an enhancement of $\mathrm{O}_{2}$ physisorption. ${ }^{8}$ Focusing on S-doped graphene (SG), it is evident that the d-orbitals of the embedded sulfur atoms are soft nucleophiles and the local strain, due to the bigger size of $\mathrm{S}$ atoms compared to $\mathrm{C}$ atoms, favors the ORR reactivity around these sites. The latter is supported by the dramatic difference in ORR efficiency even in the case of nanocarbonbased materials with less than $1 \% \mathrm{w} / \mathrm{w}$ S-loading. ${ }^{9}$ In sharp contrast, undoped GO and exfoliated graphene, which also adsorb molecular oxygen onto their lattice, lack effective active sites for the electrocatalytic reaction. In addition, SG has an increased spin density around the doped regions, arising from the S-C bond polarization, due to the different electron 
densities of the $\mathrm{S}$ and $\mathrm{C}$ atoms, resulting in higher activity compared to intact graphene. ${ }^{8,10}$

Although the mechanisms of $\mathrm{O}_{2}$ adsorption and its electroreduction over S-functionalities are yet to be fully revealed, the $\mathrm{C}-\mathrm{S}-\mathrm{C}$ bonds, in the form of thiophene rings within the heteroatomic lattice of SG, are considered the most reactive sites for the ORR. ${ }^{11}$ Thiol groups ${ }^{12}$ and sulfur oxides ${ }^{11}$ at the edges of the doped graphitic network were also found to assist the overall ORR output.

Enriching graphene with embedded thiophene rings is an objective carried out in different ways by annealing GO in the presence of excess $p$-toluenesulfonic acid, ${ }^{13} \mathrm{Na}_{2} \mathrm{~S},{ }^{14} \mathrm{CS}_{2},{ }^{15}$ $\mathrm{H}_{2} \mathrm{~S}^{16} \mathrm{SO}_{2},{ }^{17}\left(\mathrm{NH}_{4}\right)_{2} \mathrm{SO}_{4}{ }^{18}$ Lawesson's reagent ${ }^{19}$ and benzyl disulfide. ${ }^{20}$ Another strategy to access S-doped graphene is the pyrolysis of S-rich resins under an ambient atmosphere, ${ }^{21}$ or polymerization/S-doping of small molecules. ${ }^{22}$ Elevated temperature is necessary to force the substitution of oxygen atoms by sulfur and subsequently undergo oxidative cyclization reactions of sulfur with the neighboring carbon atoms. Other strategies to access S-enriched nanocarbons involve flame pyrolysis of thiophene $\mathrm{e}^{23}$ or preparation of graphene-grafted conjugated microporous polymers based on thiophene functionalities. ${ }^{24}$ Beyond experimental observations, theoretical calculations additionally show that the incorporated S-atoms could be found either in the form of thiophene as a 5 -membered ring at structurally defected sites or in the "graphitic" form as a 6-membered ring in the case of one atom substitution (i.e. $\mathrm{C}$ by S). Studies on SG lattice models have shown that the formation of the former is thermodynamically favorable in contrast to the latter. Furthermore, studies on the density of states revealed that in the "graphitic" thiopyran conformation the energy states at the Fermi level are occupied with electrons resulting in an excellent conductivity, while the "thiophene" conformation generates a bandgap. ${ }^{7}$ Apart from S-doping of $\mathrm{GO}$, the generation of $\mathrm{C}-\mathrm{S}-\mathrm{C}$ active sites was accomplished by amorphous or microporous S-enriched carbons starting from sulfur or thiophene rich precursors. ${ }^{25}$

Focusing on the development of SG by reacting GO with Lawesson's reagent, the insertion of sulfur within the graphene lattice accompanied by thermally-induced healing of the disrupted electronic network takes place. In such a way, the presence of sulfur as an electroactive site is combined with the extended $\mathrm{sp}^{2}$ graphene domains capable of hosting $\pi$-conjugated molecules via numerous $\pi-\pi$ interactions. In fact for the latter, theoretical first principles studies showed the self-assembly of sulfur-rich poly(3-hexyl-thiophene) (P3HT) onto a graphitic scaffold, favoring a face-on orientation of the sulfur atoms of P3HT with the lattice. ${ }^{26}$

Considering the aforementioned discussion, exploring the nature and the role of S-functionalities in the ORR efficiency is of great interest for developing metal-free carbon-based nanostructured cathodes useful for fuel cells and batteries. In this work, a 2D-hybrid material based on a well-defined starshaped conjugated oligothiophene immobilized onto S-doped graphene was prepared and the impact of the oligothiophene/ graphene interactions towards (photo)electrocatalysis for the
ORR was studied. The non-covalent decoration of SG by the synthesized oligothiophene $\mathbf{1}$ was found to be beneficial for lowering the onset potential for the ORR compared to pristine SG, while in the presence of light a further improvement was witnessed by $60 \%$ increment of the cathodic current and the significant $34 \mathrm{mV}$ drift of the onset potential to more positive values.

\section{Results and discussion}

The presence of three hexyl-chains in a terthiophene-functionalized planar trithienobenzene (TTB) material 1 benefits enhanced solubility in common organic solvents upon interaction with SG, which otherwise forms unstable dispersions. In addition, these solubilizing chains are beneficial for allowing smoother processing of the $\mathbf{1} / \mathbf{S G}$ ensemble. Furthermore, recently we showed that linear oligothiophenes, possessing three or nine conjugated rings carrying similar hexyl chains, can be efficiently assembled onto exfoliated graphene via $\pi-\pi$ stacking interactions contributing to the development of strong intrahybrid electronic communication upon photoillumination. ${ }^{27}$ On top, the star-shape structure of $\mathbf{1}$ is essential for increasing the surface contact with the graphene network due to the presence of the planar TTB core. This particular branched structure possesses a larger surface than a linear conjugated thiophene chain and consequently an increased contact area with the SG sheets, a beneficial property for the development of more efficient intra-ensemble van der Waals interactions. As a result, oligothiophene 1 molecules were effectively physisorbed around the electrocatalytic active regions of SG, where chemical and structural defects, due to S-atoms and healing of the distorted graphene lattice, respectively, coexist. Furthermore, the visible light harvesting ability of oligothiophene $\mathbf{1}$ allowed performing ORR photoelectrocatalytic studies.

Star-shaped oligothiophene 1, consisting of a terthiophenefunctionalized planar trithienobenzene core, was obtained by a five-step chemical synthesis route as presented in Scheme 1. The synthetic process initiated from a microwave-assisted Stille coupling reaction between 2,5-dibromo-3-hexylthiophene and 2-tributyl-stannylthiophene afforded terthiophene 2 . Markedly, microwave irradiation aided the acceleration of the otherwise slow coupling reaction, while simultaneously impeding competing side reactions. Then, 2 was treated with $\mathrm{N}$-bromosuccinimide (NBS) in the dark to yield mono-brominated terthiophene 3 , which is actually a $1: 1$ mixture of terthiophenes carrying the hexyl-chain either at C-3 or C-4 of the central thiophene core. The presence of structural isomers in 3 neither interferes with the electronic and structural properties of the compound nor affects those of the target material 1 , since the position of the alkyl chains at C-3 or C-4 do not disturb the effective conjugation length. Next, two sequential Sonogashira coupling reactions were performed to obtain the alkyne-terminated terthiophene 4 , which was then attached to 1,3,5-triiodo-2,4,6-trichlorobenzene ${ }^{28}$ affording the 


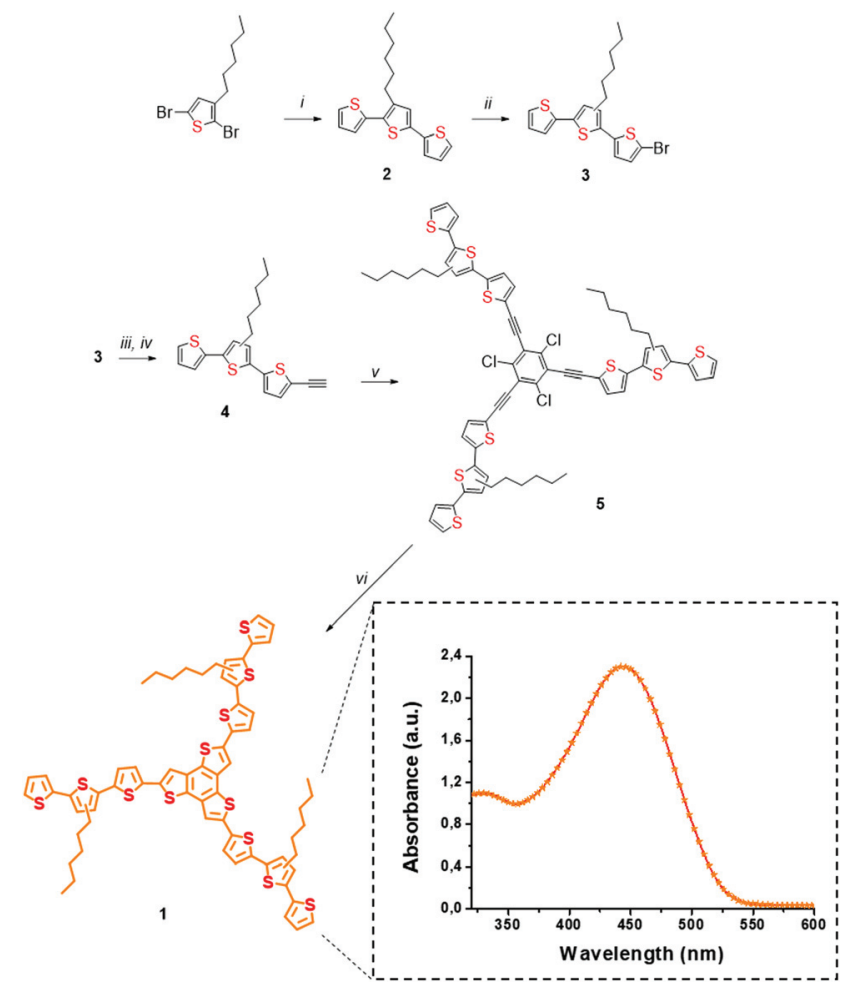

Scheme 1 Synthesis of star-shaped oligothiophene 1. Reagents and conditions: (i) 2-Tributyl-stannylthiophene, Cul, $\mathrm{Pd}\left(\mathrm{PPh}_{3}\right)_{4}, 120 \mathrm{~W}$, $120^{\circ} \mathrm{C}$, dry DMF, $\mathrm{O}_{2}$ free. (ii) $\mathrm{N}$-Bromosuccinimide, dry DCM, in the dark, $0{ }^{\circ} \mathrm{C}$ to r.t. (iii) Trimethyl-ethynylsilane, $\mathrm{Cul}, \mathrm{Pd}\left(\mathrm{PPh}_{3}\right)_{4}, \mathrm{dry} \mathrm{Et}_{3} \mathrm{~N}$, dry THF, under $\mathrm{N}_{2}, 100{ }^{\circ} \mathrm{C}$. (iv) Excess $\mathrm{KF}, \mathrm{THF} / \mathrm{MeOH}$, r.t. (v) 1,3,5-Tribromo2,4,6-trichlorobenzene, Cul, $\mathrm{Pd}\left(\mathrm{PPh}_{3}\right)_{4}$, dry $\mathrm{Et}_{3} \mathrm{~N}$, dry DCM. (vi) Excess $\mathrm{Na}_{2} \mathrm{~S}, \mathrm{NMP}, 180^{\circ} \mathrm{C}$. Inset: UV-Vis spectrum of 1 recorded in THF.

star-shaped template $\mathbf{5}$, the precursor of the target star-shaped conjugated oligothiophene 1. Finally, nucleophilic attack of sulfur ions from sodium sulfide to the carbon-carbon triplebond of $\mathbf{5}$, followed by hetero-cyclization in a two-stepone-pot reaction $^{29}$ yielded the fused heterocyclic TTB core in material 1.

The structures of $\mathbf{1}$ and of all thiophene-based precursors 2-5 were verified by ${ }^{1} \mathrm{H}$ and ${ }^{13} \mathrm{C}$ NMR spectroscopy (ESI, Fig. S1-S6 $\dagger$ ). Briefly, in the ${ }^{1} \mathrm{H}$ NMR spectrum of 1 (ESI, Fig. S6†) well resolved doublets, due to the outer thiophene ring at $7.22,7.16$ and $7.11 \mathrm{ppm}$ with a $1: 1: 1$ ratio, were identified, while also the proton doublets of the three thiophene rings fused to the TTB core at $7.07 \mathrm{ppm}$ and the characteristic signal of the first methylene group of the alkyl chain attached to the thiophene at $2.70 \mathrm{ppm}$ were evident. As far as the ${ }^{13} \mathrm{C}$ NMR spectrum is concerned, two major regions of aliphatic and conjugated carbons are present at 1-32 ppm (6 major equivalent signals) and 123-137 ppm (16 equivalent carbon signals), respectively (ESI, Fig. S6†). Additional verification for the structure of $\mathbf{1}$ arose from MALDI-TOF-MS, showing the presence of the molecular ion at 1237 amu (ESI, Fig. S7 $\dagger$ ). The electronic absorption spectrum of 1 has a broad intense absorption in the visible region centered at $440 \mathrm{~nm}$ (inset of Scheme 1). The latter arises from the unique star-shaped struc- ture, since analogous alkyl-substituted terthiophenes are poor absorbers above $350 \mathrm{~nm} .^{28}$

In parallel, thermal treatment of commercially available GO in diglyme with Lawesson's reagent, as both the sulfur source and reducing agent, ${ }^{30}$ afforded SG. Markedly, SG is a promising substrate electrocatalyst for the ORR, attributed to both the incorporation of sulfur-active sites and the thermal selfhealing of the graphitic lattice occurred during the heating period of the thionation reaction. ${ }^{31}$ During the process, partial recovery of the $\mathrm{sp}^{2}$ framework takes place, resulting in a conductive network doped with embedded sulfur atoms. Next, the as-prepared SG was added to a THF solution of $\mathbf{1}$ and the mixture was briefly sonicated and then stirred for 18 hours. After that period, it was centrifuged, the supernatant was decanted and the precipitate was isolated and washed with dichloromethane to remove completely any unbound $\mathbf{1}$. Eventually, this process gave rise to the isolation of 1/SG upon the assembly of oligothiophene $\mathbf{1}$ over the surface of SG nanosheets (Fig. 1a).

High resolution transmission electron microscopy (HR-TEM) imaging of SG revealed the presence of extended graphene sheets with lateral size in the micrometer order, while energy-dispersive X-ray spectroscopy (EDX) revealed the presence of sulfur in the lattice of SG, validating further the successful doping with sulfur atoms (Fig. 1b). HR-TEM and EDX analysis of 1/SG nanoensembles revealed the preservation of the morphology of SG and the existence of sulfur, respectively (Fig. 1b).

Vibrational spectroscopy has shed light on the structural characteristics of SG and 1/SG. Concerning SG nanosheets, Raman spectroscopy revealed the D-band at around $1350 \mathrm{~cm}^{-1}$ related to structural defects in $\mathrm{sp}^{3}$-hybridized carbon and the G-band at around $1600 \mathrm{~cm}^{-1}$ attributed to the in-plane vibration of the resonant $\mathrm{sp}^{2}$ carbon-carbon lattice (Fig. 2a). In general, the latter mode is sensitive to chemical doping, and therefore, has been commonly employed to detect the type of doping in nanocarbon materials and graphene in particular. The incorporation of S-atoms within the graphitic $\mathrm{sp}^{2}$ network induces n-doping to $\mathbf{S G},{ }^{32}$ as indicated by the down-shift of the G-band by $20 \mathrm{~cm}^{-1}$ versus the value registered for GO (Fig. 2b). Moreover, the relative intensity of the $D / G$ ratio was employed as a means to evaluate the disorder degree. Evidently, the D/G ratio for SG was increased as compared to the one registered for GO (2.1 vs. 1.53, respectively), an observation directly related to the self-healing/reduction of graphene during the thionation reaction. ${ }^{13}$ The latter observation further points to an increased defect density in graphene sheets due to S-doping. ${ }^{33}$ The supramolecular interactions of $\mathbf{1}$ with SG were similarly expected to further shift the G-band to lower frequencies due to charge transfer phenomena from the thiophene-rich 1 to the graphene lattice. Indeed, an additional $3 \mathrm{~cm}^{-1}$ shift for $\mathbf{1} / \mathbf{S G}$, compared to $\mathbf{S G}$ was observed. In the reference material 1/GO, in which 1 interacts with GO, a downshift of $18 \mathrm{~cm}^{-1}$ versus the value registered for GO was identified, certifying the occurrence of charge transfer processes from the fused oligothiophene species to graphene in GO and 
a)

b)
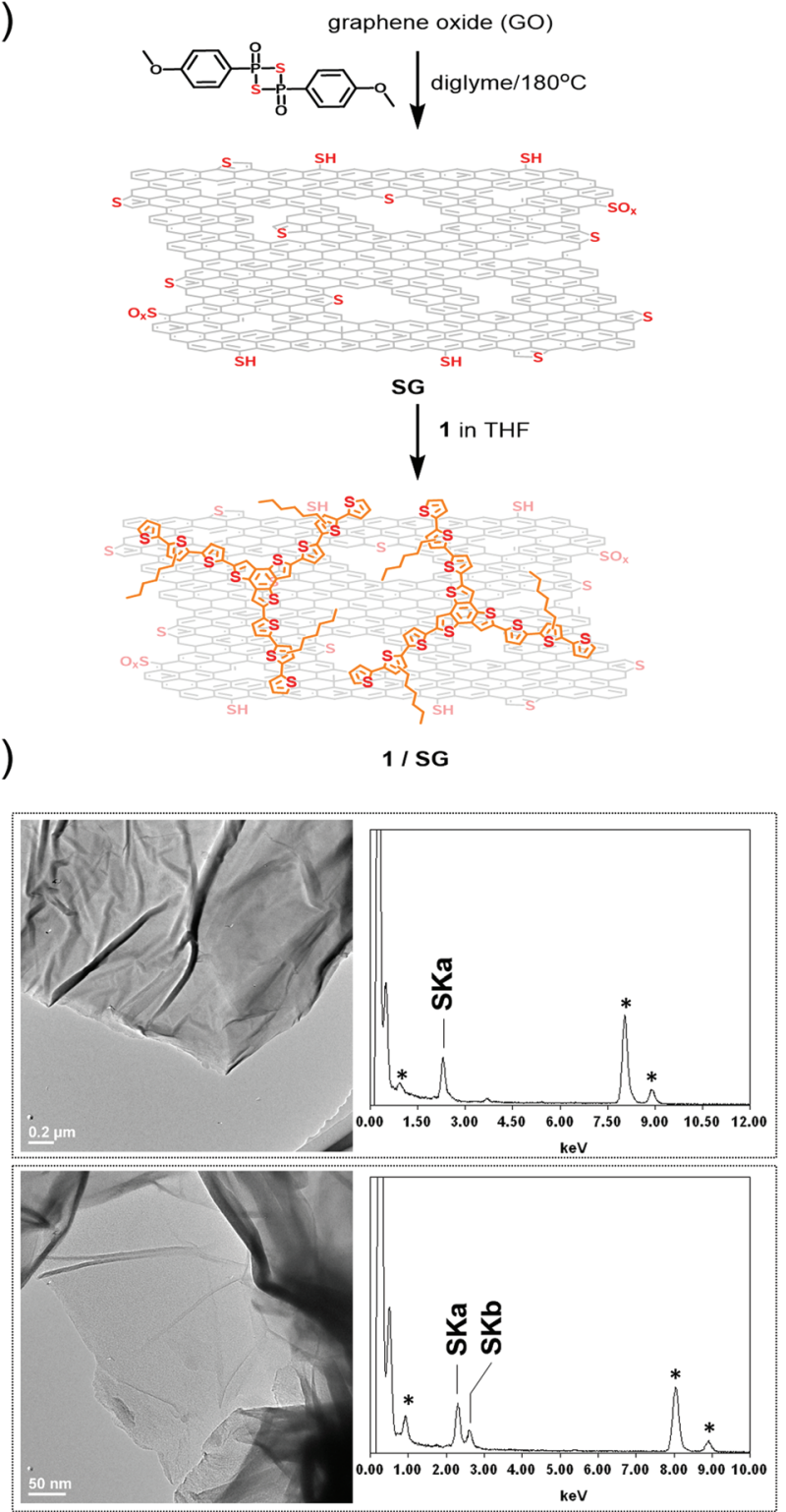

Fig. 1 (a) Preparation of the $1 / \mathrm{SG}$ ensemble featuring oligothiophene 1 immobilized onto S-doped graphene via $\pi-\pi$ interactions. (b) Representative HR-TEM images and EDX analysis of SG (upper panel) and 1/SG (lower panel). With asterisks are marked EDX signals from the copper mesh grid.

SG. Interestingly the shape of the 2D band in SG and 1/SG was found to be sharper and more intense due to the higher crystallinity of SG as compared to the distorted $\mathbf{G O}$ nanosheets. ${ }^{34}$

The ATR-IR spectrum of SG in comparison to that of GO possesses a more intense band associated with the stretching vibration of the $\mathrm{C}=\mathrm{C}$ bonds at $1655 \mathrm{~cm}^{-1}$ as a result of the partial restoration of the $\mathrm{sp}^{2}$ conjugated carbon network. Furthermore, indicative of the reduction of oxygen functionalities in SG were the diminutive intensities at $1040 \mathrm{~cm}^{-1}(\mathrm{C}-\mathrm{O})$ and $1720 \mathrm{~cm}^{-1}$ (carbonyl $\mathrm{C}=\mathrm{O}$ ). Additional distinct modes owing to $\mathrm{C}-\mathrm{S}\left(624 \mathrm{~cm}^{-1}\right), \mathrm{C}-\mathrm{S}-\mathrm{C}\left(1080 \mathrm{~cm}^{-1}\right)$ and $-\mathrm{SH}$ $\left(2662 \mathrm{~cm}^{-1}\right)$ functionalities in the IR spectrum of SG were also a)

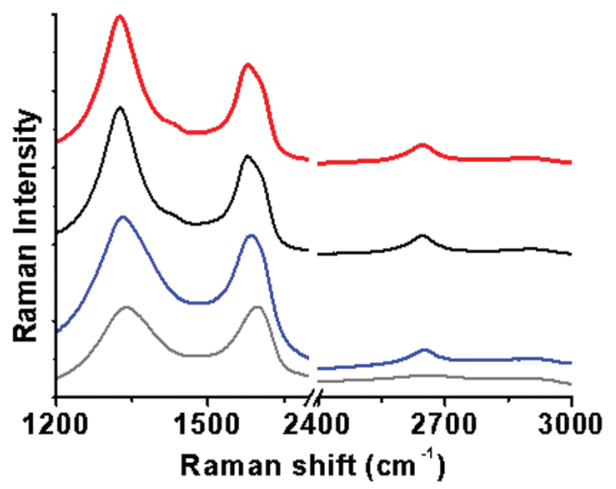

b)

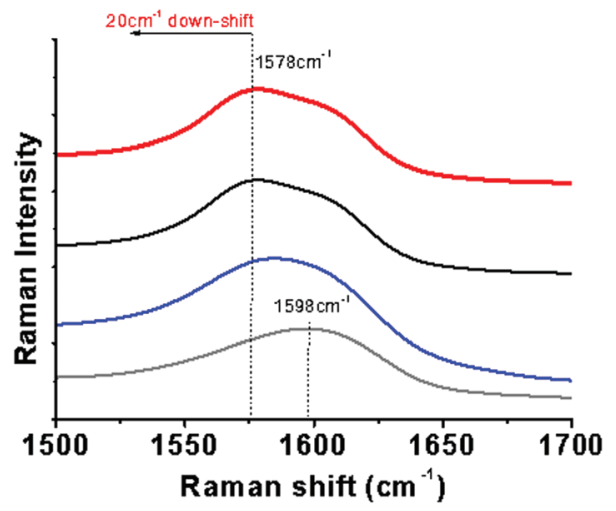

C)

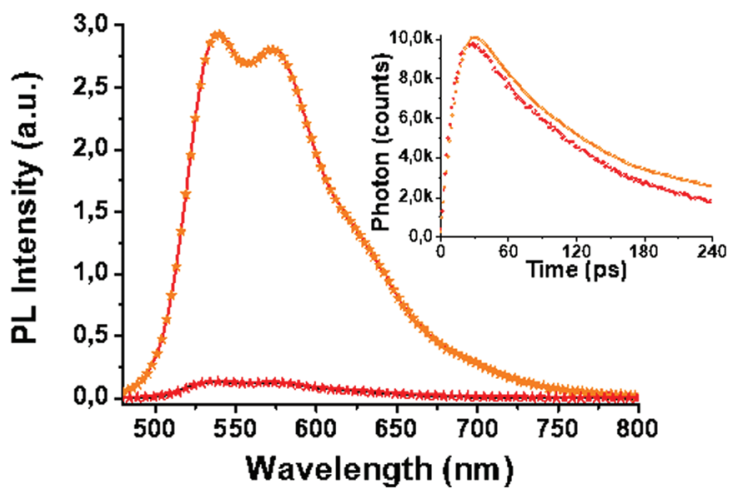

Fig. 2 (a) Full Raman spectra $\left(\lambda_{\text {exc }} 633 \mathrm{~nm}\right)$ and (b) expansion of the G-band of $1 / \mathrm{SG}$ (red), GO (grey), SG (black) and 1/GO (blue). (c) Photoluminescence spectra $\left(\lambda_{\text {exc }} 441 \mathrm{~nm}\right.$ ) of 1 (orange) and 1/SG (red) obtained in benzonitrile. Inset: Photoluminescence lifetime decay graphs.

evident (ESI, Fig. S8a†). IR spectroscopy was also employed to identify the presence of the star-shaped oligothiophene $\mathbf{1}$ within the $\mathbf{1 / S G}$ nanoensemble. In this context, the characteristic vibrations of 1 at 2921, 1461, 788 and $683 \mathrm{~cm}^{-1}$ were also present in 1/SG (ESI, Fig. S8b†), indicating the successful formation of the ensemble.

Thermogravimetric analysis (TGA) assays performed under an inert atmosphere are in line with the IR observations. For GO, a mass loss of $50 \%$ was observed in the temperature range $180-600{ }^{\circ} \mathrm{C}$, related to the decomposition of the oxygen functionalities, while the mass loss occurred at higher tempera- 
tures above $600{ }^{\circ} \mathrm{C}$ is related to the structural deformation of the graphene sheet (ESI, Fig. S9a $\dagger$ ). In contrast, SG showed higher thermal stability, losing $3 \%$ and $20 \%$ of mass at $296{ }^{\circ} \mathrm{C}$ and $806{ }^{\circ} \mathrm{C}$ (ESI, Fig. S9b $\dagger$ ), respectively, due to the less content of oxygen functionalities as a result of the thermallyinduced thiolation reaction. Furthermore, we calculated a $20 \%$ mass loading of the physisorbed oligothiophene $\mathbf{1}$ on SG from the corresponding TGA curve of $\mathbf{1 / S G}$, where two major mass loss steps were evident at $336{ }^{\circ} \mathrm{C}$ and $579{ }^{\circ} \mathrm{C}$ (ESI, Fig. S9c $\dagger$ ) attributed to the thermal decomposition of the immobilized organic molecules of $\mathbf{1}$ onto the SG nanosheets.

The immobilization of $\mathbf{1}$ over SG was further evidenced by UV-Vis absorption and photoluminescence spectroscopy assays performed in benzonitrile. The absorption maximum of oligothiophene 1 within 1/SG was found at $438 \mathrm{~nm}$ blueshifted by $8 \mathrm{~cm}^{-1}$ compared to the value registered at $446 \mathrm{~nm}$ for the free molecules of $\mathbf{1}$ in solution (ESI, Fig. S10a $\dagger$ ). Furthermore, the fluorescence spectrum of physisorbed 1 was found to be quantitatively quenched by SG within the 1/SG ensemble (Fig. 2c and ESI, Fig. S10b $\dagger$ ), for samples exhibiting equal absorption at the excitation wavelength (441 nm). Analogous strong interactions at the excited state were revealed for the 1/GO reference material (ESI, Fig. S10d $\dagger$ ), although ground state interactions were diminutive (ESI, Fig. S10c $\dagger$ ). Further insight on the electronic interplay between the two species within the $\mathbf{1 / S G}$ ensemble was delivered by timeresolved fluorescence spectroscopy. In this frame, based on time correlated single photon counting spectroscopy, the fluorescence emission decay of the immobilized oligothiophene component within 1/SG decayed $20 \mathrm{ps}$ faster $\left(t_{\mathbf{1} / \mathbf{S G}}=65 \mathrm{ps}\right)$ compared to the corresponding free molecules of $\mathbf{1}\left(t_{\mathbf{1}}=85 \mathrm{ps}\right)$ (Fig. 2c, inset). In conjunction with the fluorescence emission quenching observed in the steady-state assays, these results are supportive of electron and/or energy transfer as the decay mechanism of the formation of the singlet excited state ${ }^{1} \mathbf{1}^{*}$.

Prior to conducting the electrochemical studies concerning the electrocatalytic ORR activity of $\mathbf{1 / S G}$, cyclic voltammetry (CV) assays, in nitrogen-saturated benzonitrile with $\mathrm{TBAPF}_{6}$ as the electrolyte, to evaluate the redox properties of $\mathbf{1 / S G}$ in comparison with those of the individual components $\mathbf{1}$ and SG (ESI, Fig. S11 $\dagger$ ) were performed. In more detail, 1 revealed two reversible one-electron oxidation processes at +0.64 and +0.97 $\mathrm{V} v$ s. $\mathrm{Hg} / \mathrm{HgO}$, while within 1/SG the oxidation owing to the oligothiophene species was cathodically shifted by $10 \mathrm{mV}$ and registered at $+0.63 \mathrm{~V}$, indicating easier oxidation due to intraensemble interactions with SG. In addition, a broad reduction located at $-0.69 \mathrm{~V}$ was attributed to SG. The latter value was $6 \mathrm{mV}$ more positive and lower in intensity as compared to the reduction process registered for GO in the corresponding reference material 1/GO. From these fundamental redox data, it is clear that the electrochemical window for the ORR (i.e. +50 to $-400 \mathrm{mV}$ vs. $\mathrm{Hg} / \mathrm{HgO}$ ) is not affected by the intra-ensemble redox processes.

Initially $\mathbf{S G}$, oligothiophene $\mathbf{1}$ and the $\mathbf{1 / S G}$ ensemble were subjected to $\mathrm{CV}$ runs in an oxygen-saturated environment with an aqueous 0.1 $\mathrm{M} \mathrm{KOH}$ electrolyte. As presented in Fig. 3, all a)

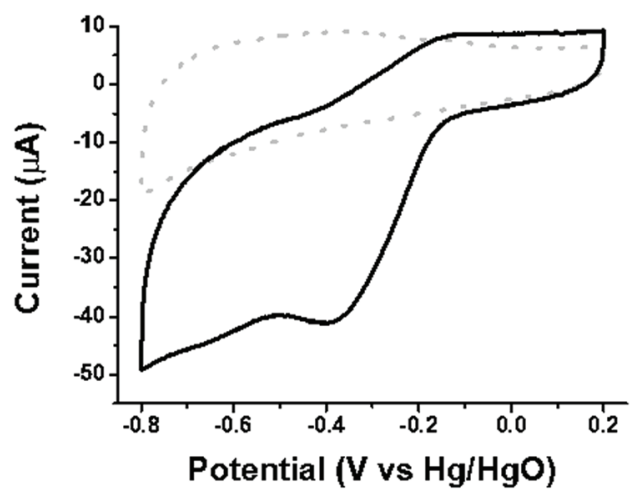

b)

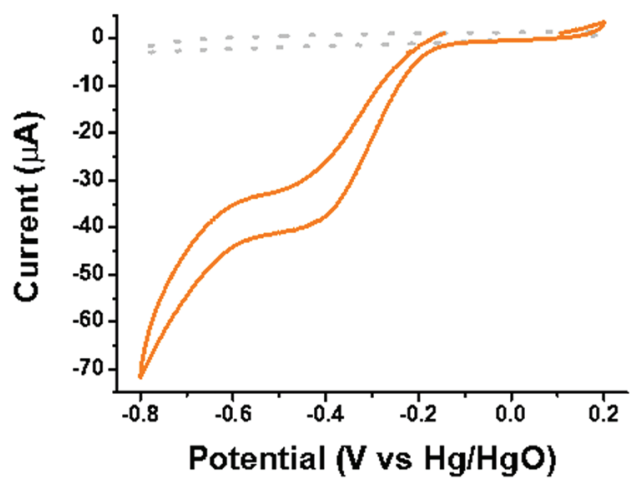

c)

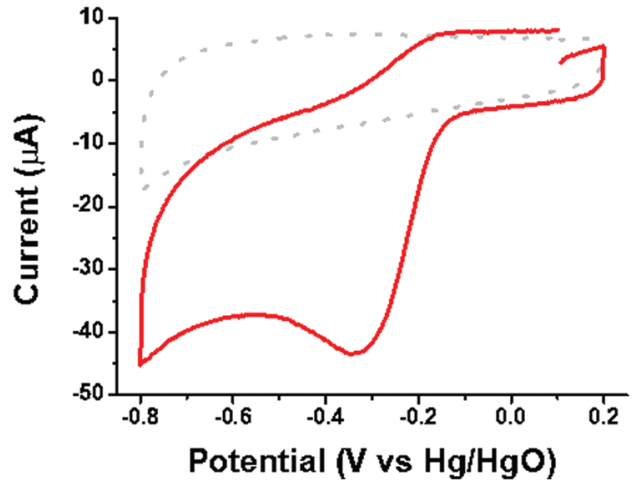

Fig. 3 Cyclic voltammographs of (a) SG, (b) 1 and (c) 1/SG in nitrogen (dotted) and oxygen (solid) saturated aqueous $0.1 \mathrm{M} \mathrm{KOH}$ electrolytes.

materials showed the characteristic cathodic current related to the oxygen reduction and the same stands for the corresponding LSV studies (ESI, Fig. S12 and S13†). The electroreduction of dissolved oxygen, with a reduction potential peak close to GO performance at $-390 \mathrm{mV}$ and a slightly more negative value by $\sim 7 \mathrm{mV}$ onset potential, was catalyzed by oligothiophene 1 (ESI, Table S1 $\dagger$ ). The $E_{\mathrm{p}}$ of $\mathbf{1 / S G}$ appeared at $-320 \mathrm{mV}$, being $57 \mathrm{mV}$ positively shifted compared to pristine SG. Taken as a reference, the $E_{\mathrm{p}}$ for the non-covalently interacting 1 with GO was registered at $-345 \mathrm{mV}$, being $45 \mathrm{mV}$ positively shifted compared to pristine GO. The $E_{\mathrm{p}}$ of $\mathbf{1 / S G}$ was very close to the value registered for the commercial $5 \% \mathrm{Pt} / \mathrm{C}$ at around $-315 \mathrm{mV}$. The electrochemical data of $\mathbf{1 / S G}$, compared with 
those owing to 1, GO, 1/GO and 5\% Pt/C materials, are collectively presented in ESI, Table S1.† Based on these results, it is clearly demonstrated that the electrocatalytic output for the ORR efficiency of 1/SG was not an overlay of the two individual components, $\mathbf{1}$ and SG, but rather attributed to a synergistic effect in which the enhanced overall performance is due to the presence of the conjugated thiophene rings in close proximity to the S-doped graphene.

The electrocatalytic properties of $\mathbf{1 / S G}$ toward the ORR were further screened by linear sweep voltammetry (LSV) acquired by the rotating disk electrode (RDE) at different rotation rates 400-3600 rpm (ESI, Fig. S14 $\dagger$ ) and chronoamperometry (CA) assays in an oxygen-saturated aqueous $0.1 \mathrm{M} \mathrm{KOH}$ electrolyte. Fig. 4a shows ORR polarization curves for 1/SG and SG obtained at a rotation rate of $1600 \mathrm{rpm}$, where, in both cases, the characteristic plateau of the 4-electron mechanism is absent, indicating a major 2-electron reduction pathway and minor 4 -electron reduction, as previously shown. ${ }^{31}$ Although the oxygen electroreduction abides by the indirect 2-electron mechanism in both $\mathbf{1 / S G}$ and SG, the immobilization of $\mathbf{1}$ onto
SG induces significant improvement in the ORR performance. Indeed, the ORR $E_{\text {onset }}$ for $\mathbf{1} / \mathbf{S G}$ was found at $-210 \mathrm{mV}$, which is $40 \mathrm{mV}$ lower compared to the $E_{\text {onset }}$ for SG (i.e. $-250 \mathrm{mV}$ ), while the half-wave potential for $\mathbf{1 / S G}$ was $-330 \mathrm{mV}$, which is $50 \mathrm{mV}$ lower compared to the corresponding value registered for SG $(-380 \mathrm{mV})$ with a slight increment in the diffusion-limiting current density $\left(j_{\mathrm{d}}\right)$ by $10 \%$. Next, the kinetic current density $\left(j_{\mathrm{k}}\right)$ for 1/SG was determined at $-270 \mathrm{mV} v s$. $\mathrm{Hg} / \mathrm{HgO}$ by using the Koutecky-Levich (K-L) equation and it was found to be $0.33 \mathrm{~mA} \mathrm{~cm}^{-2}$ (Fig. 4b), being 3.3 times greater than that of SG. Further information about the ORR kinetics can be extracted by constructing the mass transfer corrected Tafel plots (Fig. 4c). The Tafel slope for $\mathbf{1 / S G}$ was determined to be $-45 \mathrm{mV} \mathrm{dec}^{-1}$ in the low current density region (region I) and

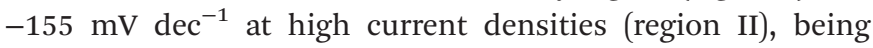
clearly lower than those determined for SG (-70 and $-166 \mathrm{mV} \mathrm{dec}^{-1}$, in regions I and II, respectively). The latter result implies higher catalytic activity towards the ORR for 1/SG as the overpotential increases faster with the current density. ${ }^{35}$ Overall, these findings, summarized in Table 1, a)

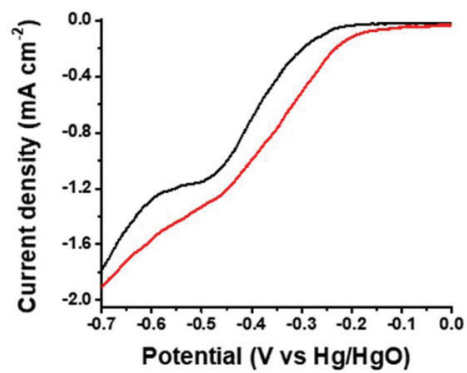

c)

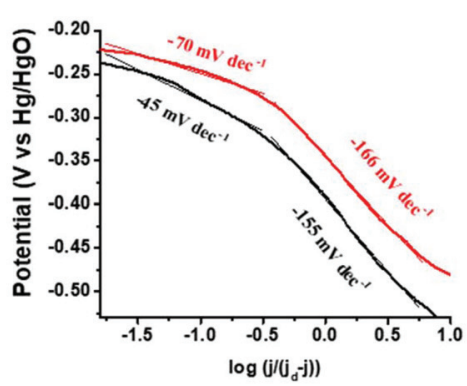

b)

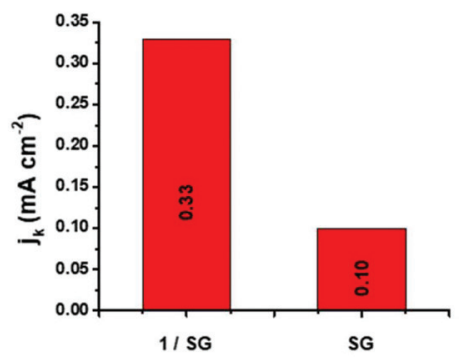

d)

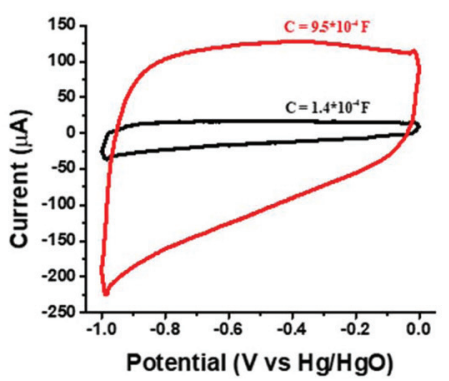

e)

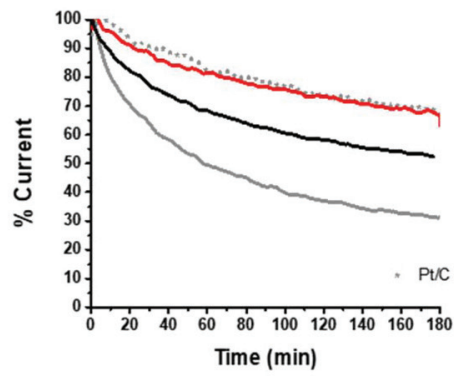

Fig. 4 (a) ORR polarization curves at $1600 \mathrm{rpm}$ for SG (black) and $1 / \mathrm{SG}$ (red) recorded in the $\mathrm{O}_{2}$ saturated aqueous $0.1 \mathrm{M}$ KOH electrolyte. (b) The corresponding kinetic current density values obtained at $-270 \mathrm{mV}$ vs. $\mathrm{Hg} / \mathrm{HgO}$ via the $\mathrm{K}-\mathrm{L}$ equation. (c) Tafel plots for SG (black) and $1 / \mathrm{SG}$ (red). Data derived from Fig. 3a and b. (d) Capacitance curves for SG (black) and 1/SG (red) recorded in the $\mathrm{N}_{2}$ saturated aqueous $0.1 \mathrm{M}$ KOH electrolyte at a scan rate of $0.2 \mathrm{~V} \mathrm{~s}^{-1}$. (e) Chronoamperometry graphs of 1/SG (red), SG (black), 1/GO (grey) and commercial Pt/C (grey scatter) recorded in the $\mathrm{O}_{2}$ saturated aqueous $0.1 \mathrm{M} \mathrm{KOH}$ electrolyte at $-0.3 \mathrm{~V}$ vs. $\mathrm{Hg} / \mathrm{HgO}$. 
Table 1 Summarized electrochemical data, recorded by linear sweep voltammetry (LSV) acquired by the rotating disk electrode (RDE), at $1600 \mathrm{rpm}$, in the oxygen saturated aqueous $0.1 \mathrm{M} \mathrm{KOH}$ electrolyte

\begin{tabular}{|c|c|c|}
\hline \multirow[b]{2}{*}{ Electrochemical parameters } & \multicolumn{2}{|l|}{ Material } \\
\hline & SG & 1/SG \\
\hline Onset potential (mV vs. $\mathrm{Hg} / \mathrm{HgO})$ & -250 & -210 \\
\hline Half-wave potential $(\mathrm{mV} v s . \mathrm{Hg} / \mathrm{HgO})$ & -380 & -330 \\
\hline Diffusion-limited current density $\left(\mathrm{mA} \mathrm{cm}^{-2}\right)$ & 1.15 & 1.27 \\
\hline Kinetic current density $\left(\mathrm{mA} \mathrm{cm}^{-2}\right)$ & -0.10 & -0.33 \\
\hline Tafel slopes $\left(\mathrm{mV} \mathrm{dec}{ }^{-1}\right)$ & $-70 /-166$ & $-45 /-155$ \\
\hline Capacitance (F) & $1.4 \times 10^{-4}$ & $9.5 \times 10^{-4}$ \\
\hline Activity loss (within 3 hours) & $>50 \%$ & $23 \%$ \\
\hline
\end{tabular}

highlight the critical role of thiophene rings in $\mathbf{1}$ for the electrocatalytic performance of the $\mathbf{1 / S G}$ ensemble.

The strong intra-ensemble electronic interactions witnessed by UV-Vis, Raman and photoluminescence spectroscopy may further polarize the C-S bonds of SG furnishing more efficient active sites for the ORR. ${ }^{8,10}$ Considering that the active site density is closely related to the capacitance, ${ }^{36}$ a possible explanation of the enhancement mechanism is given below. It is known that the insertion of sulfur functionalities across the graphene lattice results in enhanced capacitance, possibly, arising from narrow micropores within the lattice created during the doping/healing process. ${ }^{37}$ Performing CV runs for the pristine SG nanosheets and the $\mathbf{1 / S G}$ ensemble, a $\mathbf{7}$-fold increment in the $\mathbf{1} / \mathbf{S G}$ capacitance, being $9.5 \times 10^{-4} \mathrm{~F}$, over that of SG, being $1.4 \times 10^{-4} \mathrm{~F}$, by integrating the average grapharea derived by voltammographs at different scan rates, was observed (ESI, Fig. S15a and $b \dagger$ ). Both values are higher than the capacitance of the starting GO, being $0.8 \times 10^{-4} \mathrm{~F}$ (ESI, Fig. S15c †). The insertion of sulfur functionalities and healing of the lattice are responsible for the increased capacitance of SG, while the $\mathbf{7}$-fold increment to $\mathbf{1 / S G}$ is attributed to the presence of the adsorbed star-shaped oligothiophene $\mathbf{1}$ onto S-doped graphene (Fig. 4a and ESI, Fig. S14 $†$ ). As a result, the conjugated thiophenes were beneficial for the electrosorption of the dissolved oxygen and electrolyte ions, consequently enhancing the ORR output as previously described. Notably, the immobilization of $\mathbf{1}$ onto SG does not generate new micropores, however, we hypothesize that the electronic interactions between the thiophene rings and the conducting S-doped graphene are responsible for the enhanced activity.

The durability of $\mathbf{1 / S G}$ was evaluated versus continuous current flow in an oxygen-saturated aqueous $0.1 \mathrm{M} \mathrm{KOH}$ electrolyte at $-0.3 \mathrm{~V}$ at $1600 \mathrm{rpm}$. Chronoamperometry assays for 1/SG revealed a current loss of $23 \%$ after 3 hours, a value identical to the corresponding one due to the commercial $5 \% \mathrm{w} / \mathrm{w}$ Pt/C (Fig. 4e). Markedly, in reference 1/GO the current loss exceeded $70 \%$ and probably this is owing to the electroreduction of oxygen species on the nanocarbon's surface.

A synopsis of the data acquired for the recently developed S-enriched nanocarbon ORR electrocatalysts is provided in Table 2 . Generally, the kinetic current density value $\left(j_{\mathrm{k}}\right)$, determined in the kinetic region of the LSV curve (i.e. close to the onset potential), is among the most important parameters considered for the ORR activity assessment of different electrocatalysts. In this context, S-doped graphene produced by thermal treatment of $\mathrm{GO} /$ porous silica sheets with $\mathrm{H}_{2} \mathrm{~S}^{16 b}$ exhibited a $j_{\mathrm{k}}$ value of $0.15 \mathrm{~mA} \mathrm{~cm}{ }^{-2}$ while S-doped graphene synthesized by thiophene pyrolysis ${ }^{24}$ exhibited a $j_{\mathrm{k}}$ value of $0.40 \mathrm{~mA} \mathrm{~cm}{ }^{-2}$. Furthermore, S-enriched conjugated polymer nanosheets unveiled high $j_{\mathrm{k}}$ values ranging between 0.21 and $0.60 \mathrm{~mA} \mathrm{~cm}{ }^{-2} \cdot{ }^{25,26}$ Based on these data, the currently prepared and examined 1/SG ensemble can be classified among the toprated S-enriched nanocarbon catalysts for oxygen electroreduction.

Finally, taking into account the light harvesting properties of oligothiophene $\mathbf{1}$ in the visible region and the evidenced photoinduced intra-ensemble electronic interactions within 1/SG, we investigated the impact of light irradiation on ORR electrocatalysis. The $\mathbf{1 / S G}$ ensemble was deposited on transparent fluorine-doped tin oxide glass substrates, immersed in the $\mathrm{O}_{2}$ saturated aqueous $0.1 \mathrm{M} \mathrm{KOH}$ electrolyte and illuminated with a conventional $500 \mathrm{~W}$ halogen lamp (the band-gap of $\mathbf{1 / S G}$ was calculated to be $2.37 \mathrm{eV}$ by absorption spectroscopy, see ESI,

Table 2 Comparison of the ORR performance parameters of 1/SG with that of SG and other S-enriched nanocarbons reported in the literature

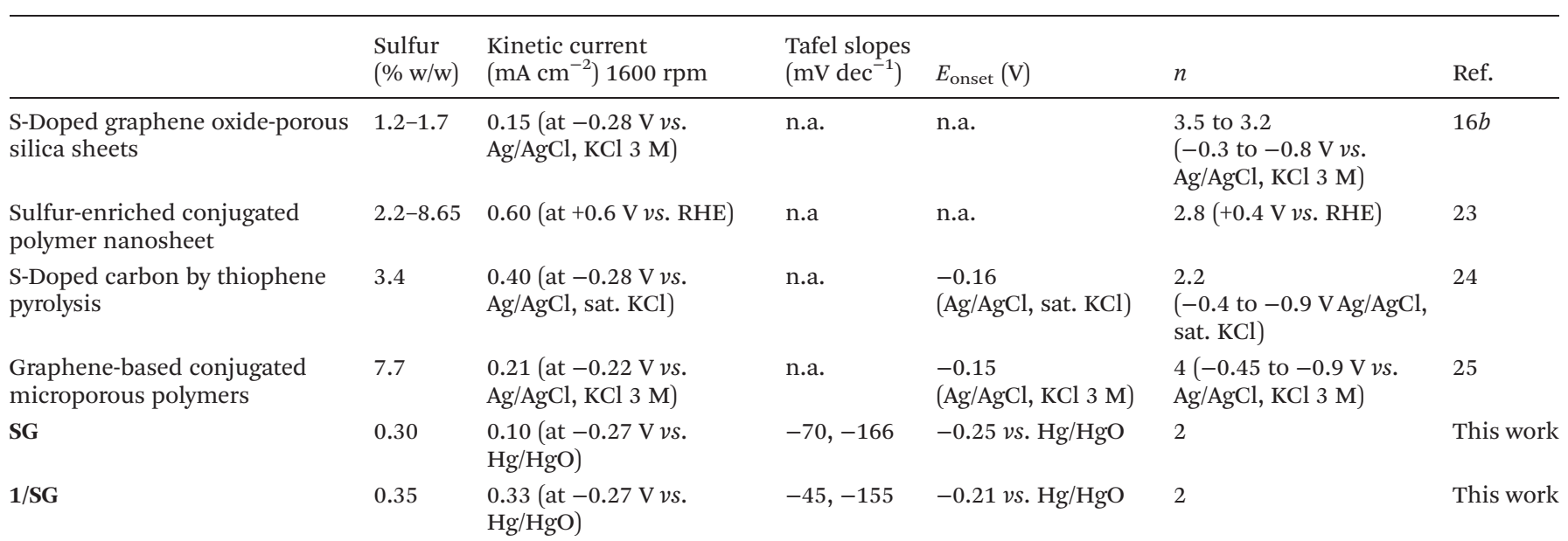




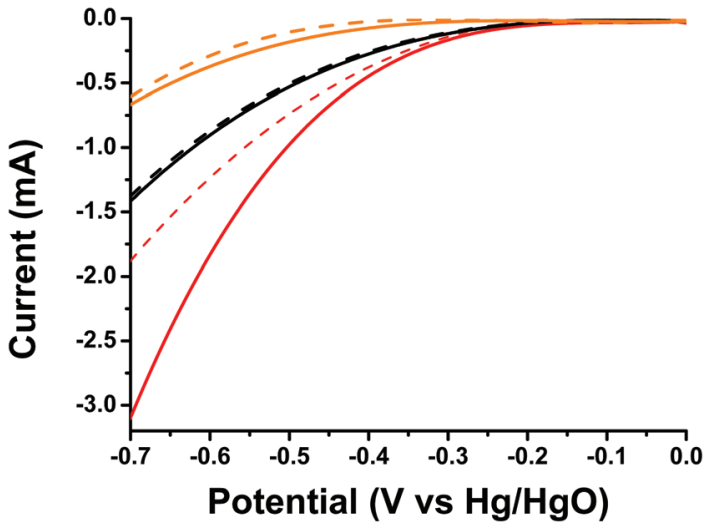

Fig. 5 LSV curves of oligothiophene 1 (orange), SG (black) and 1/SG (red), recorded under light illumination (solid) and dark (dashed) conditions, in the $\mathrm{O}_{2}$ saturated aqueous $0.1 \mathrm{M} \mathrm{KOH}$ electrolyte.

Table 3 Comparison of potential ( $E_{\text {onset }}$ ) and current $(/)$ values for ORR electrocatalysis by 1, SG and 1/SG in the presence and absence of light irradiation

\begin{tabular}{|c|c|c|}
\hline Material & $\begin{array}{l}E_{\text {onset }}(\mathrm{mV}) / I(\mathrm{~mA}) \text { at }-0.7 \mathrm{~V} \\
\text { Dark }\end{array}$ & Light irradiation \\
\hline 1 & $-411 /-0.6$ & $-380 /-0.65$ \\
\hline SG & $-265 /-1.36$ & $-263 /-1.39$ \\
\hline 1/SG & $-247 /-1.87$ & $-213 /-3.10$ \\
\hline
\end{tabular}

Fig. S16 ${ }^{\dagger}$ ). Performing LSV runs, the generated photocurrent at $-0.7 \mathrm{~V}$ for $\mathbf{1} / \mathrm{SG}$, being $-3.10 \mathrm{~mA}$, was found to be increased by $60 \%$ compared to the current recorded under dark conditions being $-1.87 \mathrm{~mA}$ (Fig. 5). Furthermore, the $E_{\text {onset }}$ of the photoexcited ensembles, registered at $-213 \mathrm{mV}$, was found to be $34 \mathrm{mV}$ more positive compared to the value obtained under dark conditions, suggesting easier reduction of the dissolved oxygen molecules in the presence of light. It is evident that analogous photoresponse was absent in the case of pristine oligothiophene $\mathbf{1}$ and SG employed as reference materials in the study (Table 3).

As manifested by Raman spectroscopy as well as steady state and time resolved photoluminescence spectroscopy, under visible light illumination strong interactions take place between the physisorbed photoexcited oligothiophene molecules and S-doped graphene within 1/SG. This is to say that the singlet excited state ${ }^{1} \mathbf{1}^{*}$ is formed and deactivated via charge/energy-transfer leading to charge-separation, similar to recent reports on fullerene-based materials. ${ }^{38,39}$ Then, in the presence of dissolved oxygen molecules, the intra-ensemble charge separated state decays via transfer of electrons to the electrocatalytic cycle of oxygen reduction. The latter mechanism is in line with the evidenced amplified current for 1/SG under irradiation conditions, since it contributes to higher electron flow, from the photoexcited oligothiophene $\mathbf{1}$ to oxygen via SG. Considering the absence of an analogous observation for pristine oligothiophene $\mathbf{1}$, it is highlighted that the presence of SG nanosheets is critical for the stabilization of the photoinduced charge separation within 1/SG and the electron transfer to oxygen, thus improving the overall ORR photoelectrocatalysis.

\section{Experimental}

\section{General}

All chemicals were commercially available and used without further purification unless otherwise stated. Steady state UV-Vis electronic absorption spectra were recorded on a PerkinElmer (Lambda 19) UV-Vis-NIR spectrophotometer. Steady-state emission spectra were recorded on a Fluorolog3 Jobin Yvon-Spex spectrofluorometer (model GL3-21). Picosecond time-resolved fluorescence spectra were measured by the time-correlated single photon counting (TCSPC) method on a Nano-Log spectrofluorometer (Horiba JobinYvon), by using a laser diode as an excitation source (NanoLED, $375 \mathrm{~nm}$ ) and a UV-vis detector TBX-PMT series (250-850 $\mathrm{nm}$ ) by Horiba JobinYvon. Lifetimes were evaluated with the DAS6 Fluorescence-Decay Analysis Software. MicroRaman scattering measurements were performed at room temperature in backscattering geometry using a RENISHAW inVia Raman microscope equipped with a CCD camera and a Leica microscope. A 2400 lines per mm grating was used for all measurements, providing a spectral resolution of $\pm 1 \mathrm{~cm}^{-1}$. As an excitation source the $\mathrm{He} / \mathrm{Ne}$ laser $(633 \mathrm{~nm})$ was used. Measurements were carried out with 60 seconds of exposure time at varying numbers of accumulations. The laser spot was focused on the sample surface using a long working distance $50 \times$ objective. Raman spectra were collected on numerous spots on the sample and recorded with a Peltier cooled CCD camera. The data were collected and analyzed with Renishaw Wire and Origin software. Electrochemical measurements were carried out in a standard three-compartment electrochemical cell using a rotating disk electrode (RDE) setup from Metrohm Autolab connected to an EG\&G Princeton Applied Research potentiostat/galvanostat (Model PARSTAT 2273A) connected to a personal computer running PowerSuite software. As a counter electrode, a platinum wire was used, and as a reference a $\mathrm{Hg} / \mathrm{HgO}$ (aqueous $0.1 \mathrm{M} \mathrm{KOH}$ electrolyte) electrode was placed into a Luggin capillary. The working electrode was a RDE with a glassy carbon (GC) disk (geometric surface area, $0.071 \mathrm{~cm}^{2}$ ) or a static GC electrode. The working electrode was cleaned before each experiment through polishing with a cloth and 6, 3 and $1 \mathrm{~mm}$ diamond paste. The ORR measurements were realized at room temperature in oxygen-saturated aqueous $0.1 \mathrm{M} \mathrm{KOH}$. Linear sweep voltammetry (LSV) measurements on the RDE of different materials were conducted at different rotation rates recorded with a scan rate of $5 \mathrm{mV} \mathrm{s}^{-1}$. The kinetic current densities $\left(j_{\mathrm{k}}\right)$ were calculated using the Koutecky-Levich (K-L) equation:

$$
1 / j=1 / j_{\mathrm{d}}+1 / j_{\mathrm{k}}
$$

where $j$ and $j_{\mathrm{d}}$ are the experimentally measured and the diffusion-limited current densities, respectively. Tafel plots 
(potential vs. $\left.\log \left(j_{\mathrm{k}}\right)\right)$ were calculated in the mixed kineticdiffusion region from the following equation:

$$
j_{\mathrm{k}}=j /\left(j_{\mathrm{d}}-j\right)
$$

at a single electrode rotation rate $(\omega=1600 \mathrm{rpm})$. The capacitance values were calculated from the CV curves obtained in nitrogen-saturated aqueous $0.1 \mathrm{M} \mathrm{KOH}$ according to the following equation:

$$
C=\int I \mathrm{~d} V / \Delta V \times n
$$

where $C(\mathrm{~F})$ is the specific capacitance; $\int I \mathrm{~d} V(\mathrm{C})$ is the integrated area of the CV curve; $\Delta V(\mathrm{~V})$ is the potential window and $v$ is the scan rate $\left(\mathrm{V} \mathrm{s}^{-1}\right)$.

The voltammographs shown in Fig. S10† were recorded using a GC working electrode and platinum wires were used as counter and pseudo-reference electrodes $\left(\mathrm{Fc} / \mathrm{Fc}^{+}\right.$as an internal reference) and 0.1 $\mathrm{M} \mathrm{TBAPF}_{6}$ in acetonitrile as the electrolyte. $\mathrm{TBAPF}_{6}(98 \%)$ was recrystallized three times from acetone and dried in a vacuum at $100{ }^{\circ} \mathrm{C}$ before being used as the electrolyte. Before each experiment, the cell was purged with Ar for 30 seconds. For the photoelectrocatalytic studies all materials were deposited on FTO-coated glass substrates (surface resistivity $\sim 7 \Omega \mathrm{Sq}^{-1}$ ) from benzonitrile solutions and dried under vacuum. As a light source a conventional linear $(118 \mathrm{~mm}) 500$ W halogen lamp was used. Mid-IR spectra in the region of 550-4000 $\mathrm{cm}^{-1}$ were obtained on an FTIR spectrometer (Equinox 55 from Bruker Optics) equipped with a single reflection diamond ATR accessory (Dura-Samp1IR II by SensIR Technologies). ${ }^{1} \mathrm{H}$ and ${ }^{13} \mathrm{C}$ NMR spectra were acquired with a Varian $300 \mathrm{MHz}$ spectrometer. HR-TEM measurements were carried out using a JEM-2100F (JEOL) high-resolution fieldemission gun TEM operated at $80 \mathrm{keV}$ at room temperature and under a pressure of $10^{-6} \mathrm{~Pa}$. HR-TEM images were recorded with a charge-coupled device with an exposure time of typically 1 second.

Synthesis of compound 2. In a microwave glass vessel, 2,5-dibromo-3-hexylthiophene (5 mmol, $1071 \mu \mathrm{L}$ ), 2-tributylstannylthiophene $(10 \mathrm{mmol}, 3970 \mu \mathrm{L})$ and CuI $(0.45 \mathrm{mmol}$, $85.7 \mathrm{mg}$ ) were added into dry DMF $(50 \mathrm{~mL})$ and the mixture was bubbled excessively with $\mathrm{N}_{2}$ to remove the dissolved oxygen. Finally, $\mathrm{Pd}\left(\mathrm{PPh}_{3}\right)_{4}(0.45 \mathrm{mmol}, 500 \mathrm{mg})$ was added and the reaction mixture was heated at $120{ }^{\circ} \mathrm{C}$ (furnace power $120 \mathrm{~W}$ ) for 1 hour. After completion of the reaction, the black mixture, due to the decomposition of the Pd-catalyst, was filtered through a Celite pad (3 cm thick) over a P4 Büchner funnel under vacuum. The Celite pad was thoroughly washed with petroleum ether. The resulting yellow/green filtrate was washed with deionized water and the organic phase was collected and dried over anhydrous $\mathrm{MgSO}_{4}$. The dried layer was filtered and evaporated to dryness. Thiophene 2 was isolated by gravity chromatography $\left(\mathrm{SiO}_{2} /\right.$ petroleum ether) as a yellowgreenish oil, after solvent evaporation. The isolated yield was 76\%. ${ }^{1} \mathrm{H} \mathrm{NMR}\left(300 \mathrm{MHz}, \mathrm{CDCl}_{3}\right): \delta=7.32(\mathrm{~m}, 1 \mathrm{H}), 7.27(\mathrm{~m}$, $1 \mathrm{H}), 7.18(\mathrm{~m}, 2 \mathrm{H}), 7.08(\mathrm{~m}, 1 \mathrm{H}), 7.04(\mathrm{~m}, 2 \mathrm{H}), 2.76(\mathrm{~m}, 2 \mathrm{H})$, $1.68(\mathrm{~m}, 2 \mathrm{H}), 1.46(\mathrm{~m}, 6 \mathrm{H}) 0.92(\mathrm{~m}, 3 \mathrm{H}) \mathrm{ppm} ;{ }^{13} \mathrm{C}$ NMR $\left(75 \mathrm{MHz}, \mathrm{CDCl}_{3}\right): \delta=140.42,137.44,135.98,135.21,129.71$, $127.97,127.4,126.59,125.98,125.51,14.46,123.71,31.79$, $30.69,27.11,22.76,17.70,14.22 \mathrm{ppm}$.

Synthesis of compound 3 . Compound 2 (0.76 mmol, $254 \mathrm{mg}$ ) was dissolved in dry dichloromethane $(20 \mathrm{~mL})$, in the absence of light, and the mixture was cooled at $0{ }^{\circ} \mathrm{C}$. Then, in the absence of light, NBS (0.68 mmol, $122 \mathrm{mg})$ was added in two equal portions every 30 minutes and the mixture was allowed to reach room temperature and stirred for 24 hours. Afterwards, the solution was evaporated to dryness and dissolved in petroleum ether. The solid residues were removed by filtration and the filtrate was passed through a $\mathrm{SiO}_{2} /$ petroleum ether column affording thiophene 3. Isolated yield $70 \%$. ${ }^{1} \mathrm{H}$ NMR (300 MHz, $\left.\mathrm{CDCl}_{3}\right): \delta=7.21(\mathrm{~m}, 1 \mathrm{H}), 7.15(\mathrm{~m}, 1 \mathrm{H}), 7.01$ $(\mathrm{m}, 3 \mathrm{H}), 6.87(\mathrm{~m}, 1 \mathrm{H}), 2.68(\mathrm{~m}, 2 \mathrm{H}), 1.62(\mathrm{~m}, 2 \mathrm{H}), 1.32(\mathrm{~m}, 6 \mathrm{H})$ and $0.90(\mathrm{~m}, 3 \mathrm{H}) \mathrm{ppm}$.

Synthesis of compound 4. Compound 3 (0.37 mmol, $132 \mathrm{mg})$ was mixed with trimethyl-ethynylsilane $(0.55 \mathrm{mmol}$, $79 \mu \mathrm{L})$, CuI (0.03 mmol, $6 \mathrm{mg})$ and dry trimethylamine $(1 \mathrm{~mL})$ in dry THF $(10 \mathrm{~mL})$ and bubbled with $\mathrm{N}_{2}$ to remove the dissolved air. Finally the catalyst $\mathrm{Pd}\left(\mathrm{PPh}_{3}\right)_{4}(0.03 \mathrm{mmol}, 39 \mathrm{mg})$ was added and the mixture was heated at $100{ }^{\circ} \mathrm{C}$ for 18 hours. After completion of the reaction, the mixture was allowed to cool at room temperature. The black mixture was filtered through a Celite pad ( $3 \mathrm{~cm}$ thick) over a $\mathrm{P} 4$ Büchner funnel. Petroleum ether was used to wash the product from the pad, affording a yellow/green solution. The organic phase was extracted with deionized water and dried over anhydrous $\mathrm{MgSO}_{4}$. Then, it was filtered, the filtrate was evaporated to dryness and the yellow/green oil TMS-protected thiophene derivative was used directly in the next step. The intermediate compound TMS-protected thiophene derivative was dissolved in THF ( $3 \mathrm{~mL})$ and methanol $(5 \mathrm{~mL})$ and then solid potassium fluoride (10 mmol, $580 \mathrm{mg}$ ) was added and the reaction mixture was left under stirring for 3 hours. TLC chromatography with petroleum ether as the eluent revealed the consumption of the starting material and the formation of a new product. The mixture was evaporated to dryness and petroleum ether was added to dissolve the product. The solid residues were filtered and the filtrate was passed through a column packed with $\mathrm{SiO}_{2}$ /petroleum ether to afford compound 4 as a bright yellow oil. The isolated yield was $60 \%$. ${ }^{1} \mathrm{H}$ NMR $\left(300 \mathrm{MHz}, \mathrm{CDCl}_{3}\right): \delta=7.22(\mathrm{~m}, 2 \mathrm{H}), 7.16(\mathrm{~m}, 1 \mathrm{H}), 7.02(\mathrm{~m}, 2 \mathrm{H})$, $6.96(\mathrm{~m}, 1 \mathrm{H}), 3.41(\mathrm{~s}, 1 \mathrm{H}), 2.73,(\mathrm{~m}, 2 \mathrm{H}), 1.65(\mathrm{~m}, 2 \mathrm{H}), 1.33(\mathrm{~m}$, $6 \mathrm{H})$ and $0.90(\mathrm{~m}, 3 \mathrm{H}) \mathrm{ppm}$.

Synthesis of compound 5. Compound 4 (0.28 mmol, $100 \mathrm{mg}$ ), 1,3,5-tribromo-2,4,6-trichlorobenzene (0.25 mmol, $140 \mathrm{mg})$, dry triethylamine $(2 \mathrm{~mL})$ and $\mathrm{CuI}(0.03 \mathrm{mmol}, 5 \mathrm{mg})$ were added into dry dichloromethane $(100 \mathrm{~mL})$. The mixture was bubbled with $\mathrm{N}_{2}$ to remove the dissolved oxygen. Then, Pd $\left(\mathrm{PPh}_{3}\right)_{4}(0.03 \mathrm{mmol}, 29 \mathrm{mg})$ was added and the reaction mixture was sealed and heated at $100{ }^{\circ} \mathrm{C}$ for 18 hours. Then, an additional amount of compound 4 (0.28 mmol, $100 \mathrm{mg})$ was added and the mixture was degassed again prior to the addition of $\mathrm{Pd}\left(\mathrm{PPh}_{3}\right)_{4}(0.03 \mathrm{mmol}, 29 \mathrm{mg})$ and heated at $80{ }^{\circ} \mathrm{C}$ 
for 18 hours. The latter step was followed once more (addition of the third equivalent). After the addition of three equivalents of compound $\mathbf{4}$, the mixture was cooled down to r.t. and passed through a Celite pad over a P4 Büchner funnel. Petroleum ether was used to wash the product from the pad, affording a bright red solution. The organic phase was washed with deionized water, dried over anhydrous $\mathrm{MgSO}_{4}$, filtered and evaporated to dryness. The viscous red oil residue was passed three times through a column packed with $\mathrm{SiO}_{2} /$ petroleum ether to afford $40 \mathrm{mg}$ of 5 as a red solid. The isolated yield was $12 \% .{ }^{1} \mathrm{H} \mathrm{NMR}\left(300 \mathrm{MHz}, \mathrm{CDCl}_{3}\right): \delta=7.29(\mathrm{~m}$, $3 \mathrm{H}), 7.24$ (m, 3H), 7.18 (m, 3H), 7.01 (m, 9H), 2.75 (m, 6H), 1.67 (m, 6H), $1.40(\mathrm{~m}, 18), 0.92(\mathrm{~m}, 9 \mathrm{H}) \mathrm{ppm} .{ }^{13} \mathrm{C} \mathrm{NMR}(75 \mathrm{MHz}$, $\left.\mathrm{CDCl}_{3}\right): \delta=141.51,140.59,139.47,136.91,136.09,134.98$, 128.74, 127.98, 126.84, 126.79, 125.39, 124.81, 124.04, 121.17, 79.30, 77.61, 31.71, 30.48, 29.72, 29.32, 22.68 and $14.16 \mathrm{ppm}$.

Synthesis of star-shaped oligothiophene 1. Compound 5 (0.06 mmol, $74 \mathrm{mg}$ ) was dissolved in NMP (15 mL) forming a yellow solution and heated in the presence of excess solid $\mathrm{Na}_{2} \mathrm{~S}$ at $180{ }^{\circ} \mathrm{C}$ for 3 hours, where the consumption of compound 5 was followed by TLC with petroleum ether as the eluent. The red solution was allowed to reach r.t. and was washed with brine and petroleum ether. The organic phase was separated and evaporated to dryness. The residual red solid was passed through a column packed with $\mathrm{SiO}_{2} /$ petroleum ether affording star-shaped $\mathbf{1}$ as a bright red solid. Isolated yield $75 \mathrm{mg}, 100 \%$. ${ }^{1} \mathrm{H}$ NMR (300 $\left.\mathrm{MHz}, \mathrm{CDCl}_{3}\right): \delta=$ 7.22 (d, 3H), 7.18 (d, 3H), 7.13 (d, 3H), $7.11(\mathrm{~m}, 3 \mathrm{H}), 7.04(\mathrm{~m}$, 9H), 2.77 (m, 6H) ppm. ${ }^{13} \mathrm{C}$ NMR (75 MHz, CDCl3): $\delta=140.67$, $137.28,136.80,136.11,135.91,135.42$, 135.24, 129.44, 128.02, 126.82 , 126.51, 125.66, 124.59, 124.43, 124.13, 123.81, 32.09, $31.83,30.62,30.47,29.68,29.48,29.41,22.85,22.78,14.33$ and $14.27 \mathrm{ppm}$.

Preparation of SG. For the thionation reaction, commercially available GO (10 mg) and Lawesson's reagent in a 1:20 mass ratio were mixed in diglyme $(50 \mathrm{~mL})$ and heated under nitrogen for 3 hours at $200{ }^{\circ} \mathrm{C}$. Then the reaction mixture was allowed to reach r.t. and filtered through a PTFE membrane under vacuum. The solid residue was washed thoroughly with toluene, methanol and dichloromethane. The as-derived filter cake was dispersed in methanol with the aid of a sonication bath and centrifuged affording SG as a black fine powder.

Preparation of $\mathbf{1} / \mathrm{GO}$ and $\mathbf{1} / \mathrm{SG}$ ensembles. In $5 \mathrm{~mL}$ of a THF solution of $\mathbf{1}\left(1.5 \mathrm{mg} \mathrm{mL}^{-1}\right)$, GO or SG $(1 \mathrm{mg})$ was added. The mixture was homogenized under mild sonication treatment for 5 minutes and left to stir for $18 \mathrm{~h}$. After that period, the reaction mixture was centrifuged, the supernatant was decanted and the precipitate was isolated and washed with dichloromethane to remove completely any unbound $\mathbf{1}$.

\section{Conclusions}

Summarizing, the synthesis and immobilization of starshaped oligothiophene 1 onto S-doped graphene sheets, yielding 1/SG ensembles, as efficient electrocatalysts for the ORR, was accomplished. Employing complementary spectroscopic, thermal and microscopy imaging techniques the success of preparation was proved. In addition, detailed electrochemical and electrocatalytic assays revealed improved activity and stability towards the ORR in alkaline media for $\mathbf{1 / S G}$, outperforming not only the individual components of the ensemble $\mathbf{1}$ and SG but also GO and 1/GO tested as references. The high catalytic activity of $\mathbf{1 / S G}$, evidenced by the increased kinetic current density and low Tafel slope values, was attributed to the (a) presence of chemical defects, induced by the insertion of the electron rich sulfur within the lattice of SG, (b) existence of structural defects, due to the generation of vacancies along the carbon lattice in SG, and (c) high and homogeneous coverage of the SG surface by the sulfur-rich star-shaped oligothiophene 1. Further analysis on the ORR kinetics showed a major 2-electron mechanism for $\mathbf{1 / S G}$.

Strong photoinduced intra-ensemble electronic interactions were also witnessed in $\mathbf{1} / \mathbf{S G}$. Hence, the light harvesting properties of 1 were exploited towards ORR photoelectrocatalysis, where a better performance for $\mathbf{1 / S G}$ in terms of lower $E_{\text {onset }}$ and amplified current generated was observed under light irradiation. In contrast, analogous studies on oligothiophene 1 and pristine SG did not show further catalytic improvement. Collectively, the critical role of SG nanosheets in the stabilization of the light-induced charge separation within 1/SG and the subsequent electron transfer to oxygen is highlighted. Overall, the current findings can serve as significant milestones for the future design of high-performance ORR nonmetal doped-graphene-based electrocatalysts. ${ }^{40}$ This in turn will lead to the development of alternative non-precious cathode electrocatalysts to replace platinum in energy-related applications.

\section{Conflicts of interest}

There are no conflicts to declare.

\section{Acknowledgements}

We acknowledge support of this work by the project "Advanced Materials and Devices" (MIS 5002409) which is implemented under the "Action for the Strategic Development on the Research and Technological Sector", funded by the Operational Programme "Competitiveness, Entrepreneurship and Innovation" (NSRF 2014-2020) and co-financed by Greece and the European Union (European Regional Development Fund). Financial support through a Ph.D. scholarship by the General Secretariat for Research and Technology (GSRT) Hellenic Foundation for Research and Innovation (HFRI) to D. K. P. (Grant 95) is also acknowledged. We are indebted to Prof. M. Prodromidis, at the Department of Chemistry, University of Ioannina, Greece, for kindly providing the RDE system, to Prof. A. G. Coutsolelos and Dr G. Charalambidis at the Department of Chemistry, University of Crete, Greece, for 
kind assistance with the MALDI-TOF-MS acquisition, and to Prof. H. Shinohara and his group at the Department of Chemistry, Nagoya University, Japan, for kindly providing access to perform the HR-TEM and EDX measurements.

\section{Notes and references}

1 F. Möller, S. Piontek, R. G. Miller and U.-P. Apfel, Chem. Eur. J., 2018, 24, 1471.

2 D. Grumelli, B. Wurster, S. Stepanow and K. Kern, Nat. Nanotechnol., 2013, 4, 2904.

3 (a) X. Liu and L. Dai, Nat. Rev. Mater., 2016, 1, 16064; (b) D. He, H. Tang, Z. Kou, M. Pan, X. Sun, J. Zhang and S. Mu, Adv. Mater., 2017, 29, 1601741.

4 (a) M. Shao, Q. Chang, J.-P. Dodelet and R. Chenitz, Chem. Rev., 2016, 116, 3594; (b) A. A. Gewirth, J. A. Varnell and A. M. DiAscro, Chem. Rev., 2018, 118, 2313.

5 (a) K. Gong, F. Du, Z. Xia, M. Durstock and L. Dai, Science, 2009, 323, 760; (b) X. Wang, G. Sun, P. Routh, D.-H. Kim, W. Huang and P. Chen, Chem. Soc. Rev., 2014, 43, 7067.

6 (a) C. Wang, L. Ma, L. Liao, S. Bai, R. Long, M. Zuo and Y. Xiong, Sci. Rep., 2013, 3, 2580; (b) D. Higgins, M. A. Hoque, M. H. Seo, R. Wang, F. Hassan, J.-Y. Choi, M. Pritzker, A. Yu, J. Zhang and Z. Chen, Adv. Funct. Mater., 2014, 24, 4325.

7 A. G. Garcia, S. E. Baltazar, A. H. Romero Castro, J. F. Perez Robles and A. Rubio, J. Comput. Theor. Nanosci., 2008, 5, 2221.

8 L. Zhang, J. Niu, M. Li and Z. Xia, J. Phys. Chem. C, 2014, 118, 3545.

9 S.-A. Wohlemuth, R. J. White, M.-G. Willinger, M.-M. Titirici and M. Antonietti, Green Chem., 2012, 14, 1514.

10 I.-Y. Jeon, S. Zhang, L. Zhang, H.-J. Choi, J.-M. Seo, Z. Xia, L. Dai and J.-B. Baek, Adv. Mater., 2013, 25, 6138.

11 (a) W. Kiciński, M. Szala and M. Bystrzejewski, Carbon, 2014, 68, 1; (b) H. Shen, E. Gracia-Espino, J. Ma, K. Zang, J. Luo, L. Wang, S. Gao, X. Mamat, G. Hu, T. Wagberg and S. Guo, Angew. Chem., Int. Ed., 2017, 56, 13800.

12 C. K. Chua and M. Pumera, ACS Nano, 2015, 9, 4193.

13 Y. Li, J. Wang, X. Li, D. Geng, M. N. Banis, Y. Tang, D. Wang, R. Li, T.-K. Sham and X. Sun, J. Mater. Chem., 2012, 22, 20170.

14 (a) Y. Chen, J. Li, T. Mei, X. Hu, D. Liu, J. Wang, M. Hao, J. Li, J. Wang and X. Wang, J. Mater. Chem. A, 2014, 2, 20174; (b) L. Chen, X. Cui, Y. Wang, M. Wang, R. Qiu, Z. Shu, L. Zhang, Z. Hua, F. Cui, C. Wei and J. Shi, Dalton Trans., 2014, 43, 3420.

15 J. Park, Y. J. Jang, Y. J. Kim, M. Song, S. Yoon, D. H. Kim and S.-J. Kim, Phys. Chem. Chem. Phys., 2014, 16, 103.

16 (a) C. Liang, Y. Wang and T. Li, Carbon, 2015, 82, 506; (b) S. Yang, L. Zhi, K. Tang, X. Feng, J. Maier and K. Müllen, Adv. Funct. Mater., 2012, 22, 3634.
17 H. L. Poh, P. Šimek, Z. Sofer and M. Pumera, ACS Nano, 2013, 7, 5262.

18 D. He, Z. Kou, Y. Xiong, K. Cheng, X. Chen, M. Pan and S. Mu, Carbon, 2014, 66, 312.

19 H. Liu, L. Zhang, Y. Guo, C. Cheng, L. Yang, L. Jiang, G. Yu, W. He, Y. Liu and D. Zhu, J. Mater. Chem. C, 2013, 1, 3104.

20 Z. Yang, Z. Yao, G. Li, G. Fang, H. Nie, Z. Liu, X. Zhou, X. Chen and S. Huang, ACS Nano, 2012, 6, 205.

21 (a) Y. Zhang, M. Chu, W. Deng, Y. Tang, M. Ma and Q. Xie, Chem. Commun., 2014, 50, 6382; (b) X. Liu and M. Antonietti, Adv. Mater., 2013, 25, 6284.

22 Y. Su, Z. Yao, F. Zhang, H. Wang, Z. Mics, E. Cánovas, M. Bonn, X. Zhuang and X. Feng, Adv. Funct. Mater., 2016, 26, 5893.

23 S. Inamdar, H.-S. Choi, P. Wang, M. Y. Song and J.-S. Yu, Electrochem. Commun., 2013, 30, 9.

24 Z. Zhuang, F. Zhang, D. Wu, N. Forler, H. Liang, M. Wagner, D. Gehrig, M. R. Hansen, F. Laquai and Z. Feng, Angew. Chem., Int. Ed., 2013, 52, 9668.

25 D. Liu, L. Dai, X. Lin, J.-F. Chen, J. Zhang, X. Feng, K. Müllen, X. Zhu and S. Dai, Adv. Mater., 2019, 31, 1804863.

26 D. H. Kim, H. S. Lee, H.-J. Shin, Y.-S. Bae, K.-H. Lee, S.-W. Kim, D. Choi and J.-Y. Choi, Soft Mater., 2013, 9, 5355.

27 A. Stergiou, H. B. Gobeze, I. D. Petsalakis, S. Zhao, H. Shinohara, F. D'Souza and N. Tagmatarchis, Nanoscale, 2015, 7, 15840.

28 M. Sonoda, A. Inaba, K. Itahashi and Y. Tobe, Org. Lett., 2001, 3, 2419.

29 T. Kashiki, S. Shinamura, M. Kohara, E. Miyazaki, K. Takimiya, M. Ikeda and H. Kuwabara, Org. Lett., 2009, 11, 2473.

30 D. K. Perivoliotis, Y. Sato, K. Suenaga and N. Tagmatarchis, ACS Appl. Energy Mater., 2018, 1, 3869.

31 A. Ambosi, C. K. Chua, A. Bonanni and M. Pumera, Chem. Rev., 2014, 114, 7150.

32 (a) Q. Su, S. Pang, V. Alijani, C. Li, X. Feng and K. Müllen, Adv. Mater., 2009, 21, 3191; (b) A. Stergiou and N. Tagmatarchis, ACS Appl. Mater. Interfaces, 2016, 8, 21576; (c) H. Liu, Y. Liu and D. Zhu, J. Mater. Chem., 2011, 21, 3335 .

33 X. Zhang, J. Zhu, C. S. Tiwary, Z. Ma, H. Huang, J. Zhang, Z. Lu, W. Huang and Y. Wu, ACS Appl. Mater. Interfaces, 2016, 8, 10858.

34 S. Abdolhosseinzadeh, H. Asgharzadeh and H. S. Kim, Sci. Rep., 2015, 5, 10160.

35 Y. Zheng, S. Zhao, S. Liu, H. Yin, Y.-Y. Chen, J. Bao, M. Han and Z. Dai, ACS Appl. Mater. Interfaces, 2015, 7, 5347.

36 J. Benson, Q. Xu, P. Wang, Y. Shen, L. Sun, T. Wang, M. Li and P. Papakonstantinou, ACS Appl. Mater. Interfaces, 2014, 6, 19726.

37 M. Seredych and T. J. Bandosz, J. Mater. Chem. A, 2013, 1, 11717. 
38 S. Bellani, A. Ghadirzadeh, L. Meda, A. Savoini, A. Tacca, G. Marra, R. Meira, J. Morgado, F. Di Fonzo and M. R. Antognazza, Adv. Funct. Mater., 2015, 25, 4531.

39 R. M. Girón, J. Marco-Martínez, S. Bellani, A. Insuasty, H. C. Rojas, G. Tullii, m. r. Antognazza,
S. Filipone and N. Martin, J. Mater. Chem., 2016, 4, 14284.

40 I. S. Amiinu, J. Zhang, Z. Kou, X. Liu, O. K. Asare, H. Zhou, K. Cheng, H. Zhang, L. Mai, M. Pan and S. Mu, ACS Appl. Mater. Interfaces, 2016, 8, 29408. 